\title{
PERBEDAAN GANGGUAN KOGNITIF SUBJEK STROKE ISKEMIK BERDASARKAN SISI HEMIPARESIS
}

\author{
DIFFERENCE OF COGNITIVE IMPAIRMENT IN ISCHEMIC STROKE \\ PATIENTS BASED ON HEMIPARESIS SIDE \\ Gabriella, * Budi Riyanto Wreksoatmodjo, ** Andre**
}

\section{ABSTRACT}

Introduction: Cognitive impairment in stroke has a significant impact on the quality of life and is different from the location of the lesion. Patients with a lesion in the left cerebral hemisphere tend to have cognitive impairment and dementia.

Aim: This study investigates the relationship between the location of the lesion, which is manifested by hemiparesis side, and the occurrence of cognitive impairment in ischemic stroke patients.

Method: A cross-sectional study was conducted in the population of ischemic stroke patients at Atma Jaya Hospital, who were registered from January 2014 to December 2018. Cognitive function was measured by the Mini-Mental State Examination (MMSE) and Montreal Cognitive Assessment Indonesian Version (MoCA-Ina). Data were analyzed univariate and bivariate with the software program, statistical package for the social sciences (SPSS) version 25.0.

Result: There were 125 patients included in this study, which predominantly was 55 years old and older $(62.4 \%)$ and had a low education level (58.4\%). The proportion of patients with right-sided hemiparesis (54.4\%) was slightly higher than the left-side one (45.6\%). No significant relationship was observed between the hemiparesis side and every cognitive function domain measured by MMSE and MoCA-Ina (p-value >0.05).

Discussion Hemiparesis side indicating hemisphere lateralization in ischemic stroke patients showed no significant relationship with the occurrence of cognitive impairment based on MMSE and MoCA-Ina score.

Keywords: Cognitive impairment, hemisphere lateralization, ischemic stroke, MMSE score, MoCA-Ina score

\section{ABSTRAK}

Pendahuluan: Gangguan kognitif pada stroke menyebabkan penurunan kualitas hidup dan berbeda berdasarkan letak lesi. Berdasarkan letak lesi, lesi di hemisfer serebri kiri lebih sering menyebabkan gangguan kognitif dan demensia.

Tujuan: Tujuan penelitian untuk mengetahui pengaruh perbedaan letak lesi dilihat dari sisi hemiparesis terhadap gangguan kognitif pada subjek stroke iskemik.

Metode: Studi potong lintang dilakukan pada pasien stroke iskemik di RS Atma Jaya periode tahun 2014- 2018. Fungsi kognitif dinilai dengan menggunakan Mini Mental State Examination (MMSE) dan Montreal Cognitive Assesment Indonesian Version (MoCA-Ina). Analisis data dilakukan secara univariat dan bivariat menggunakan menggunakan program statistical package for the social sciences (SPSS) versi 25.0.

Hasil: Sebanyak 125 pasien tergabung dalam penelitian ini, yang sebagian besar berusia $\geq 55$ tahun $(62,4 \%)$ dan memiliki tingkat pendidikan $\leq 9$ tahun $(58,4 \%)$. Proporsi pasien dengan hemiparesis kanan $(54,4 \%)$ lebih besar daripada kiri (45,6\%). Tidak terdapat hubungan antara sisi hemiparesis dengan skor MMSE dan MoCA-Ina pada semua ranah (nilai $\mathrm{p}>0,05)$.

Diskusi: Sisi hemiparesis pasien stroke iskemik yang menunjukkan lateralisasi hemisfer serebri tidak berhubungan dengan gangguan kognitif berdasarkan skor MMSE dan MoCA-Ina.

Kata kunci: Gangguan kognitif, lateralisasi hemisfer, skor MMSE, skor MoCA-Ina, stroke iskemik

*FKIK Universitas Katolik Indonesia Atma Jaya, Jakarta; **Departmen Neurologi FKIK Universitas Katolik Indonesia Atma Jaya, Jakarta. Korespondensi: gabriellahamid21@gmail.com.

\section{PENDAHULUAN}

Stroke merupakan penyebab kematian kedua di seluruh dunia pada tahun 2015 dan penyebab utama disabilitas jangka panjang. ${ }^{1-2}$ Data Riset Kesehatan Dasar tahun 2018 menyebutkan prevalensi stroke di Indonesia sebesar 10,9\%. ${ }^{3}$ Lebih jauh lagi, stroke dapat mengakibatkan gangguan kognitif yang bisa menurunkan kualitas hidup subjek. ${ }^{4}$ Sebesar $54,5 \%$ subjek pascastroke mengalami gangguan kognitif. ${ }^{5}$
Berdasarkan hemisfer serebri yang terkena akibat stroke, lesi di hemisfer serebri kiri memiliki frekuensi, tingkat keparahan, dan mortalitas yang lebih tinggi daripada yang di hemisfer serebri kanan. ${ }^{6}$ Di samping itu, lesi di hemisfer serebri kiri juga lebih sering menyebabkan gangguan kognitif dan demensia. ${ }^{7}$

Sisi hemisfer yang terdapat lesi dapat diketahui dengan pemeriksaan neurologis. Sebagai contoh, lesi di hemisfer serebri kiri dapat menyebabkan 
hemiparesis kanan, sedangkan lesi pada hemisfer serebri kanan menyebabkan hemiparesis kiri. ${ }^{8}$

Penilaian fungsi kognitif dapat dilakukan menggunakan Mini Mental Status Examination (MMSE) dan Montreal Cognitive Assessment (MoCA). MMSE menilai gangguan kognitif pada ranah orientasi, registrasi, atensi, kalkulasi, recall, Bahasa, dan visuospasial. Adapun Montreal Cognitive Assessment Versi Indonesia (MoCA-Ina) dapat mengukur ranah kognitif visuospasial, penamaan, atensi, bahasa, abstraksi, memori tunda, dan orientasi. ${ }^{9,10}$

Penelitian yang menunjukkan perbedaan gangguan kognitif dengan menggunakan total skor menunjukkan hasil yang seragam, tetapi penelitian yang menunjukkan perbedaan kognitif pada masingmasing ranah kognitif masih menunjukkan hasil yang bervariasi. Penelitian menurut Contreras dkk menunjukkan hasil skor rerata atensi dan orientasi pada lesi hemisfer kanan lebih baik. ${ }^{9}$ Penelitian menurut Wilde menunjukkan lesi kanan memiliki skor bahasa, atensi, dan memori lebih baik, sedangkan subjek dengan lesi kiri menunjukkan hasil visuospasial lebih baik. ${ }^{11}$ Oleh sebab itu perlu diteliti perbedaan fungsi kognitif pada berbagai ranah menurut sisi hemiparesis.

\section{TUJUAN}

Mengetahui pengaruh perbedaan letak lesi yang dilihat dari sisi hemiparesis terhadap gangguan kognitif pada subjek stroke iskemik di RS Atma Jaya.

\section{METODE}

Penelitian potong lintang terhadap subjek stroke iskemik di RS Atma Jaya pada periode Januari 2014 hingga Desember 2018. Metode pengambilan sampel adalah sampel jenuh dengan estimasi besar sampel minimal berdasarkan rumus adalah 81 orang.

Kriteria inklusi adalah data subjek yang tercatat dalam Register Stroke RS Atma Jaya periode 1 Januari 2014 sampai 31 Desember 2018; terdapat kelengkapan data usia, tingkat pendidikan, gangguan motorik, MMSE, dan MoCA-Ina; serta mengalami stroke iskemik untuk pertama kalinya. Adapun kriteria eksklusi penelitian adalah subjek dengan skor National Institutes of Health Stroke Scale (NIHSS) $>15$. Poin akhir MMSE memiliki cut-off nilai normal yaitu diatas 24 dari total skor 30 poin. Nilai maksimal untuk MoCA adalah 30 poin dengan poin akhir 26 atau lebih menandakan fungsi kognitif normal.

Data yang dikumpulkan adalah usia subjek, jenis stroke yang dinilai secara diagnosis klinis, sisi hemiparesis stroke yang dilihat dari manifestasi gangguan sistem motorik, nilai MMSE yang meliputi ranah orientasi, registrasi, atensi, kalkulasi, recall, bahasa, dan visuospasial, serta nilai MoCA-Ina yang meliputi ranah visuospasial, penamaan, atensi, bahasa, abstraksi, memori tunda, dan orientasi.

Persetujuan ethical clearance didapatkan melalui surat No. 06/02/KEP-FKUAJ/2019. Analisis statistik menggunakan program statistical package for the social sciences (SPSS) versi 25.0. Analisis univariat dilakukan untuk melihat karakteristik variabel yang diteliti, yaitu usia, tingkat pendidikan, sisi hemiparesis, MMSE, dan MoCA-Ina. Analisis bivariat dilakukan untuk melihat hubungan antara masing-masing ranah kognitif pada MMSE dan MoCA-Ina dengan sisi hemiparesis. Batas kemaknaan secara statistik adalah nilai $\mathrm{p}<0,05$.

\section{HASIL}

Didapatkan 125 subjek penelitian ini yang sebagian besar berusia $\geq 55$ tahun $(62,4 \%)$ dan tingkat pendidikan sekolah dasar ( $\leq 9$ tahun) sebesar 58,4\%. Lebih banyak subjek dengan hemiparesis kanan $(54,4 \%)$ daripada kiri $(45,6 \%)$. Total skor MMSE memiliki median 25 yang berarti fungsi kognitif normal, sedangkan total skor MoCA-INA memiliki median 20 yang berarti terdapat gangguan kognitif.

Analisis bivariat menunjukkan tidak ada hubungan bermakna antara masing-masing ranah kognitif pada MMSE dengan sisi hemiparesis ( $p$ $>0,05)$. Tren yang dapat dilihat adalah hasil pada setiap ranah kognitif MMSE menunjukkan skor yang lebih tinggi pada subjek dengan sisi hemiparesis kiri daripada yang kanan (Tabel 2).

Demikian pula tidak dijumpai hubungan bermakna antara MoCA-Ina dengan sisi hemiparesis yang $(\mathrm{p}>0,05)$. Secara garis besar untuk masing-masing ranah, skor MoCA-Ina pada kelompok sisi hemiparesis kiri lebih tinggi daripada yang kanan, kecuali untuk ranah penamaan yang sama skornya (Tabel 3). 
Tabel 1. Karakteristik Sosiodemografi Subjek $(n=125)$

\begin{tabular}{lc}
\hline \multicolumn{1}{c}{ Variabel } & n (\%) \\
\hline Usia (tahun) & \\
- $<55$ tahun & $47(37,6)$ \\
- $\geq 55$ tahun & $78(62,4)$ \\
Tingkat Pendidikan & \\
- $>9$ tahun & $40(32)$ \\
- $\leq 9$ tahun & $73(58,4)$ \\
- Tidak bersekolah & $12(9,6)$ \\
Sisi Hemiparesis & \\
- Kiri & $57(45,6)$ \\
- Kanan & $68(54,4)$ \\
\hline
\end{tabular}

Tabel 2. Distribusi Nilai MMSE Berdasarkan Sisi Hemiparesis $(\mathbf{n}=125)$

\begin{tabular}{lccc}
\hline \multirow{2}{*}{$\begin{array}{c}\text { Ranah Kognitif } \\
\text { MMSE }\end{array}$} & $\begin{array}{c}\text { Kanan } \\
\text { (median; } \\
\text { rentang } \\
\text { interkuartil) }\end{array}$ & $\begin{array}{c}\text { Kiri } \\
\text { (median; } \\
\text { rentang }\end{array}$ & p* \\
interkuartil) & \\
\hline Orientasi & $9(2,75)$ & $9(2)$ & 0,580 \\
Registrasi & $3(0)$ & $3(0)$ & 0,455 \\
Atensi dan & $3(4)$ & $4(3)$ & 0,692 \\
Kalkulasi & & & \\
Recall & $1,5(3)$ & $2(2)$ & 0,202 \\
Bahasa & $7(2)$ & $8(2)$ & 0,390 \\
Visuospasial & $1(1)$ & & 0,772 \\
*Uji Mann-Whitney; MMSE: Mini Mental Status Examination; \\
SD: standar deviasi.
\end{tabular}

\section{PEMBAHASAN}

Sebagian besar sampel penelitian berusia $\geq 55$ tahun. Hal ini sesuai dengan penelitian lain yang menyatakan usia merupakan salah satu faktor risiko tidak dapat diubah (unmodifiable risk) dari stroke iskemik. Penambahan usia 10 tahun dari usia 55 tahun meningkatkan risiko penyakit stroke iskemik sebanyak 2 kali lipat. Hal ini disebabkan adanya perubahan struktur dan fungsi mikro dan makrosirkulasi berupa disfungsi endotel, gangguan autorgeulasi serebral, dan neurovascular coupling. ${ }^{12}$

Pada penelitian ini, sisi hemiparesis kanan memiliki proporsi lebih besar daripada hemiparesis kiri. Dengan kata lain, lesi di hemisfer serebri kiri lebih sering dijumpai daripada kanan. Hal ini sesuai dengan penelitian menurut Hedna dkk bahwa stroke iskemik di hemisfer serebri kiri lebih sering terjadi daripada stroke iskemik pada hemisfer serebri kanan. ${ }^{6}$

Analisis data menunjukkan tidak terdapat hubungan yang bermakna antara sisi hemiparesis dengan skor MMSE dan MoCA-Ina pada subjek stroke iskemik. Walaupun demikian, terdapat kecenderungan sisi hemiparesis kiri memiliki skor yang lebih tinggi daripada kanan. Hal ini sesuai dengan penelitian menurut Contreras dkk yang menunjukkan bahwa lesi di hemisfer serebri kiri menyebabkan gangguan fungsi kognitif lebih besar daripada lesi di hemisfer kanan. ${ }^{9}$

Ranah recall menurut MMSE dan memori tunda menurut MoCA-Ina menunjukkan hasil sesuai dengan teori sebelumnya, yaitu subjek hemiparesis kiri memiliki skor median lebih tinggi daripada yang kanan. Hal ini sesuai dengan penelitian menurut Contreras dkk bahwa subjek dengan lesi di hemisfer serebri kanan memiliki skor memori tunda pada MoCA-Ina lebih tinggi daripada subjek dengan lesi di hemisfer serebri kiri. ${ }^{9}$ Selain itu, hasil ini juga didukung oleh teori sebelumnya yang menunjukkan bahwa lesi di hemisfer serebri kiri akan menyebabkan

Tabel 3. Distribusi Nilai MoCA-Ina Berdasarkan Sisi Hemiparesis (n=125)

\begin{tabular}{lccc}
\hline \multicolumn{1}{c}{ Ranah Kognitif } & \multicolumn{2}{c}{ Sisi Hemiparesis } & \multirow{2}{*}{$\mathbf{p}^{*}$} \\
\cline { 2 - 3 } \multicolumn{1}{c}{ MoCA-Ina } & Kanan (median;rentang interkuartil) & Kiri (median;rentang interkuartil) & \\
\cline { 2 - 3 } Visuospasial & $3(4)$ & $3(4)$ & 0,284 \\
Penamaan & $3(1)$ & $3(1)$ & 0,652 \\
Atensi & $4(2,75)$ & $4(3)$ & 0,412 \\
Bahasa & $2(2)$ & $2(1,5)$ & 0,706 \\
Abstraksi & $1(2)$ & $1(1)$ & 0,184 \\
Memori & $1,5(3)$ & $2(3)$ & 0,293 \\
Orientasi & $6(1,75)$ & $6(2)$ & 0,998 \\
\hline *Uji Mann-Whitney; MoCA-Ina: Montreal Cognitive Assessment Versi Indonesia ; SD: standar deviasi.
\end{tabular}


penurunan memori verbal, angka, memori semantik, dan memori tunda, sedangkan yang kanan lebih banyak berperan dalam memori yang berhubungan dengan figur dan wajah serta memori spasial., ${ }^{9,13}$

Ranah atensi MMSE juga menunjukkan hasil yang sesuai dengan teori sebelumnya, yaitu subjek hemiparesis kiri memiliki skor rerata lebih tinggi. Hal ini menunjukkan subjek dengan lesi di kiri memiliki gangguan atensi lebih buruk dibandingkan subjek yang memiliki lesi di kanan. Temuan ini sesuai dengan Mayer dkk dan teori sebelumnya yang menjelaskan gangguan pada hemisfer serebri kiri dapat menyebabkan penurunan atensi dalam proses kalkulasi dan kognitif..$^{14-15}$

Pada penelitian ini, ranah bahasa pada MMSE menunjukkan subjek dengan hemiparesis kiri memiliki rerata skor yang lebih baik daripada kanan. Hal ini sesuai dengan teori bahwa fungsi bahasa diatur oleh area Wernicke dan Broca di hemisfer dominan yang biasanya merupakan hemisfer serebri kiri. ${ }^{13}$

Kemampuan penamaan pada MoCA-Ina pada subjek dengan hemiparesis kiri sama dengan subjek dengan hemiparesis kanan, tidak sesuai dengan teori bahwa penamaan diatur oleh area Wernicke di sisi kiri, sehingga lesi pada sisi kiri seharusnya menyebabkan gangguan penamaan lebih buruk dibandingkan lesi pada sisi kanan. ${ }^{13}$ Hal ini dapat disebabkan pada pemeriksaan ranah penamaan, selain fungsi penamaan yang melibatkan fungsi bahasa, terdapat juga fungsi integrasi persepsi dan memori yang berperan. ${ }^{16-17}$

Kemampuan abstraksi pada MoCA-Ina juga memiliki skor median yang sama pada subjek hemiparesis kiri dan hemiparesis kanan. Ranah ini dapat digunakan untuk menunjukkan kelainan pada lobus frontalis. ${ }^{13}$ Hasil penelitian ini tidak sesuai dengan penelitian menurut Murphy dkk bahwa subjek dengan kelainan di frontal kiri secara signifikan memiliki gangguan abstraksi, terutama menginterpretasikan peribahasa. ${ }^{17}$

Pada ranah orientasi dan visuospasial, hasil yang diperoleh tidak sesuai dengan teori sebelumnya karena seharusnya kedua ranah ini lebih banyak diatur oleh hemisfer non-dominan atau hemisfer serebri kanan. ${ }^{9,13}$ Pada ranah orientasi, hasil yang didapatkan mungkin disebabkan orientasi waktu, tempat, dan orang diatur oleh banyak area yang berbeda. Ketiga aspek yang dievaluasi, yaitu waktu, tempat, dan orang melibatkan korteks cingulata posterior, lobus parietalis inferior, sulkus frontalis superior, dan lobus oksipitalis. Lebih jauh lagi, aspek waktu, dan orang juga melibatkan area korteks prefrontal medial dan sulkus temporalis superior. Oleh karena adanya keterlibatan area yang saling tumpang tindih, maka perbedaan letak lesi tidak terlalu dapat dilihat. ${ }^{18}$ Pada ranah visuospasial, hasil yang didapat mungkin disebabkan oleh subjek dengan stroke di hemisfer dominan (hemisfer serebri kiri) dapat mengalami gangguan motorik pada tangan yang dominan, sehingga bisa mengakibatkan kesulitan saat mengerjakan pemeriksaan visuospasial dengan menggunakan tangan dominan (tangan kanan). ${ }^{11}$

Hasil yang tidak signifikan pada semua data bisa disebabkan rentang skor yang diperoleh sempit dan perbedaan dilihat menggunakan median, sehingga tidak terlihat banyak perbedaan yang bermakna. Hal ini bisa disebabkan penelitian ini untuk membedakan sisi lesi digunakan data sisi hemiparesis, sementara hemiparesis sendiri bisa disebabkan oleh lesi di area yang non-hemisfer. ${ }^{8}$ Hal ini bisa menyebabkan bias karena bisa saja lesi yang terjadi bukan di hemisfer dan menyebabkan hemiparesis namun tidak menyebabkan gangguan kognitif, sehingga memengaruhi hasil penelitian.

Keterbatasan penelitian adalah penelitian ini menggunakan data klinis sisi hemiparesis untuk menentukan lateralisasi hemisfer, sedangkan hemiparesis dapat disebabkan oleh lesi yang bukan pada hemisfer serebri yang terlibat dalam fungsi kognitif. Hal ini dapat memengaruhi hasil penelitian karena sampel yang diperoleh tidak semuanya memiliki lesi di hemisfer dan sampel dengan lesi non-hemisfer mungkin tidak memiliki gangguan kognitif. Selain itu, penelitian ini hanya melakukan penyesuaian terhadap skor NIHSS, sedangkan terdapat faktorfaktor lain yang dapat memengaruhi hasil penelitian diantaranya tingkat pendidikan, luas lesi, waktu pengambilan data, dan lamanya perawatan. 


\section{KESIMPULAN}

Tidak terdapat hubungan sisi hemiparesis dengan skor rerata MMSE dan MoCA-Ina pada semua ranah.

\section{DAFTAR PUSTAKA}

1. Benjamin EJ, Blaha MJ, Chiuve SE, Cushman M, Das SR, Deo R, dkk. Heart disease and stroke statistics - 2017 update: A Report From the American Heart Association. Circulation 2017;135:e146-603.

2. World Health Organization. WHO Priority diseases and reasons for inclusion: Acute Stroke. World Health Organization 2013;

3. Badan Penelitian dan Pengembangan Kesehatan Kementrian Kesehatan RI. Riset Kesehatan Dasar. Jakarta: Badan Penelitian dan Pengembangan Kesehatan Kementrian Kesehatan RI; 2018.

4. Nys GM, Van MZ, De PK, Jansen BP, De EH, Kappelle LJ. Cognitive disorders in acute stroke: prevalence and clinical determinants. Cerebrovasc Dis Basel Switz. 2007;23(5-6):408-16.

5. Johnen A, Räthe S, Lohmann H, Philipp K, Minnerup $\mathrm{J}$, Wiendl H, dkk. Frequency and risk factors associated with post-stroke dementia-an observational study on stroke patients without premorbid cognitive impairment. Der Nervenarzt. 2020;91(2):131-40.

6. Hedna VS, Bodhit AN, Ansari S, Falchook AD, Stead L, Heilman KM, dkk. Hemispheric differences in ischemic stroke: is left-hemisphere stroke more common? J Clin Neurol Seoul Korea 2013;9(2):97-102.

7. Rokhayah S, Budi H. Perbedaan Stroke Lesi Hemisfer Kiri dan Stroke Lesi Hemisfer Kanan terhadap Terjadinya Demensia di RSUD Banyumas. Sainteks 2016;13(2):33-40.

8. Ropper A, Samuels M, Klein J. Adams and Victors Principles of Neurology. Edisi ke-10. United States: McGraw-Hill Education; 2014. h. 778-885.
9. Obregon CTL. Hemispheric lateralization of stroke damage using the Montreal Cognitive Assessment. ProQuest Dissertations Publishing 2016;2016:10167932.

10. Khachiyants N, Kim K. Mini-mental Status Examination Mapping to the Corresponding Brain Areas in Dementia. Appl Technol Innov. 2012;7(2).

11. Wilde MC. Lesion location and repeatable battery for the assessment of neuropsychological status performance in acute ischemic stroke. Clin Neuropsychol. 2009;24(1):57-69.

12. Yousufuddin M, Young N. Aging and ischemic stroke. Aging. 2019;11(9):2542-4.

13. Blumenfeld H. Neuroanatomy through Clinical Cases. Edisi ke-2. Sunderland United States: Sinauer Associates, Inc; 2010. h. 879-928.

14. Mayer E, Reicherts M, Deloche G, Willadino-Braga L, Taussik I, Dordain M, dkk. Number processing after stroke: Anatomoclinical correlations in oral and written codes. J Int Neuropsychol Soc. 2003;9(06).

15. Schoenberg MR, Scott JG, Schoenberg MR, Scott JG. The little black book of neuropsychology: a syndrome-based approach. Ed ke-1. New York United States: Springer US; 2011. h. 149-58.

16. Ten Brink AF, Matthijs Biesbroek J, Kuijf HJ, Van der Stigchel S, Oort Q, Visser-Meily JMA, dkk. The right hemisphere is dominant in organization of visual search - A study in stroke patients. Behav Brain Res. 2016;304:71-9.

17. Murphy P, Shallice T, Robinson G, MacPherson SE, Turner M, Woollett K, dkk. Impairments in proverb interpretation following focal frontal lobe lesions. Neuropsychologia 2013;51(11):2075-86.

18. Peer M, Salomon R, Goldberg I, Blanke O, Arzy S. Brain system for mental orientation in space, time, and person. Proc Natl Acad Sci USA. 2015;112(35):1072-7. 